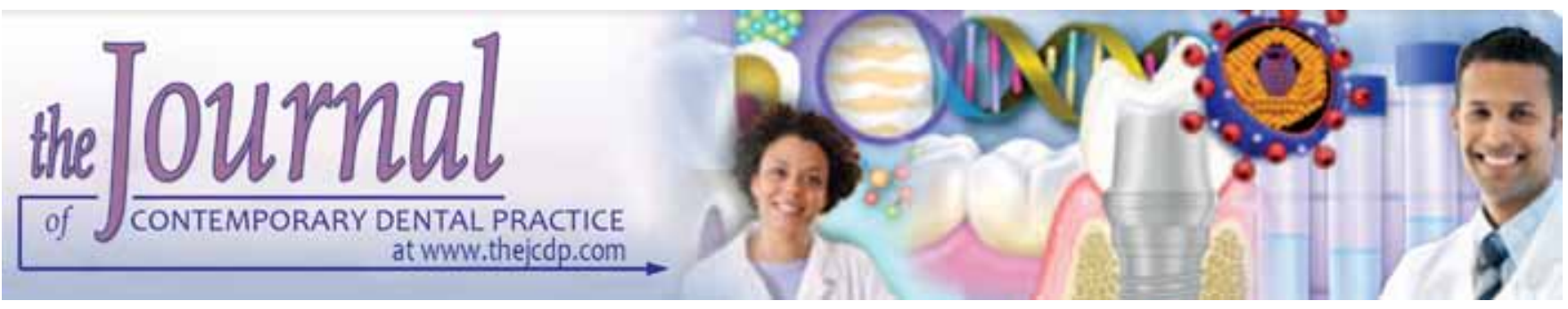

\title{
Calcifying Odontogenic Cyst: A Rare Report of A Nonneoplastic Variant associated with Cholesterol Granuloma
}

\author{
Manikkath Aparna, Mukund Gupta, Nanditha Sujir, Abhay Kamath, Monica Solomon \\ Keerthilatha Pai, Raghu Radhakrishnan
}

\begin{abstract}
Aim: To report a case of a non-neoplastic variant of calcifying odontogenic cyst (COC) with the lining epithelium showing ameloblastomatous proliferation and capsule exhibiting features of a cholesterol granuloma. The importance of delineating this histologic variant from unicystic ameloblastoma and the formation of cholesterol granuloma in this variant is discussed.
\end{abstract}

Background: Calcifying odontogenic cyst is a developmental jaw cyst, which presents itself as both the neoplastic and the non-neoplastic forms. The ameloblastomatous variant of $\mathrm{COC}$ is often mistaken for unicystic ameloblastoma and treated aggressively.

Case report: A 68-year-old female who presented with a cystic enlargement of the posterior mandible on the right side was suggestive of unicystic ameloblastoma based on radiography and initial biopsy report. Microscopic examination of the excision specimen, however, was fitting in favor of calcifying odontogenic cyst with ameloblastomatous proliferation.

Conclusion: Identifying the non-neoplastic ameloblastomatous variant of $\mathrm{COC}$ from a cystic ameloblastoma is crucial as the treatment of the two lesions vary considerably.

Clinical significance: This case emphasizes the need for thorough examination of the entire surgical specimen before arriving at an appropriate diagnosis.

Keywords: Case report, Calcifying odontogenic cyst, Ameloblastomatous proliferation, Non-neoplastic variant, Cholesterol granuloma, Surgical enucleation.

How to cite this article: Aparna M, Gupta M, Sujir N, Kamath A, Solomon M, Pai K, Radhakrishnan R. Calcifying Odontogenic Cyst: A Rare Report of a Nonneoplastic Variant associated with Cholesterol Granuloma. J Contemp Dent Pract 2013;14(6):11781182.

Source of support: Nil

Conflict of interest: None

\section{INTRODUCTION}

The calcifying odontogenic cyst (COC) is a rare developmental odontogenic cyst, which was first described by
Gorlin in 1962 as the oral counterpart of the cutaneous calcifying epithelioma of Malherbe (pilomatricoma). ${ }^{1}$ it may present as a solitary cystic lesion or a solid tumor, with varying clinical presentations and outcome. In majority of the cases, it occurs centrally within the jaw bones and occasional occurrence within the soft tissue overlying the jaw bone has also been reported. ${ }^{2}$ The unique feature of this entity is with regard to its lining epithelium consisting of ghost cells and calcification. Hyalinized areas in the capsule adjacent to the basal layer of the cystic epithelium are thought to represent dysplastic or immature dentin. Calcifying odontogenic cyst represents a heterogeneous group of lesions and there may be the concurrent presentation of COC with odontomas and other associated odontogenic tumors, such as ameloblastoma, ameloblastic fibroma and ameloblastic fibro-odontoma, making the diagnosis of COC quite challenging. ${ }^{3}$ We report a case of a non-neoplastic variant of $\mathrm{COC}$ with ameloblastomatous proliferation. The unusual occurrence of cholesterol granuloma in the cyst wall is highlighted. Use of Van Gieson stain for the presence of ghost cells is also emphasized.

\section{CASE REPORT}

A 68-year-old female patient presented to the dental clinic with a painless enlargement in the mandibular right posterior region of 1 month duration. The history did not suggest of any obvious increase in its size since its onset. Other findings, such as paresthesia and discharge from the site or dysphagia, fever and weight loss were not reported. Extraoral examination revealed a swelling on the right side of the face in the region of the body of the mandible. Intraorally, a diffuse enlargement of about $4 \times 3 \mathrm{~cm}$ was noted on the right side of the residual alveolar ridge extending from the distal aspect of the mandibular second premolar to the 
retromolar region (Fig. 1). The enlargement was bony hard in consistency.

Orthopantamogram revealed a well-defined unilocular radiolucency extending from the middle of the mandibular ramus on the right side crossing the midline to the mandibular canine on the left side. Thinning of the inferior mandibular border was also evident (Fig. 2). Plain computed tomography (CT) of the mandible showed an expansile lytic lesion of the right side of the mandible measuring $4.2 \times 3.7 \times 4.7 \mathrm{~cm}$ (Fig. 3). Owing to the large size of the lesion, residual cyst, odontogenic keratocyst, glandular odontogenic cyst and ameloblastoma were considered in the differential diagnosis.

Routine hematological investigations were not contributory as the peripheral blood counts were normal. Protein estimation of the cyst aspirate suggested that the total protein content was about $6 \mathrm{~g} / \mathrm{dl}$. Incisional biopsy revealed a cystic space lined by an odontogenic epithelium. The basal cells were hyperchromatic while the superficial cells were loosely arranged resembling the stellate reticulum like cells (Fig. 4). The connective tissue subjacent to the lining epithelium was hyalinized. Significantly, the deeper capsular tissue showed the presence of numerous cholesterol clefts and giant cells (Fig. 5) interspersed with areas of non-descript calcification. A nonspecific diagnosis of cystic ameloblastoma with concurrent association of a hybrid odontogenic tumor was made and enucleation of the lesion was advised.

Histological examination of the excision specimen revealed a cystic space lined by odontogenic epithelium with occasional collection of ghost cells in clusters (Fig. 6). Focal areas of ameloblastomatous proliferation were evident (Fig. 7). The subjacent connective tissue was hyalinized with diffuse infiltration of inflammatory cells. The connective tissue capsule showed numerous cholesterol clefts and giant cells admixed with nondescript calcification and areas of ghost cells, which was confirmed with Van Gieson special stain (Fig. 8). A diagnosis of non-neoplastic variant of $\mathrm{COC}$ with ameloblastomatous proliferation of the lining epithelium was given. The patient follow-up after 18 months of treatment suggests that the lesion has healed well with bone evidence of bone formation and no signs of any recurrence.

\section{DISCUSSION}

Calcifying odontogenic cyst represents approximately $1 \%$ of all the cysts of the jaw bones. ${ }^{4}$ Although the lesion was described for the first time in 1932 by Rywkind, Gorlin is often credited as he defined it as an entity, histologically distinct from the calcifying epithelial odontogenic tumor ${ }^{3-6}$ and hence the eponym, Gorlin cyst.
Calcifying odontogenic cyst has been traditionally categorized into the cystic and the neoplastic subtypes. The cystic variant exhibits unicystic architecture with hyperchromatic basal cells and overlying stellate reticulumlike cells. The lining epithelium shows a unifocal or multifocal intraluminal and intramural ameloblastomatous

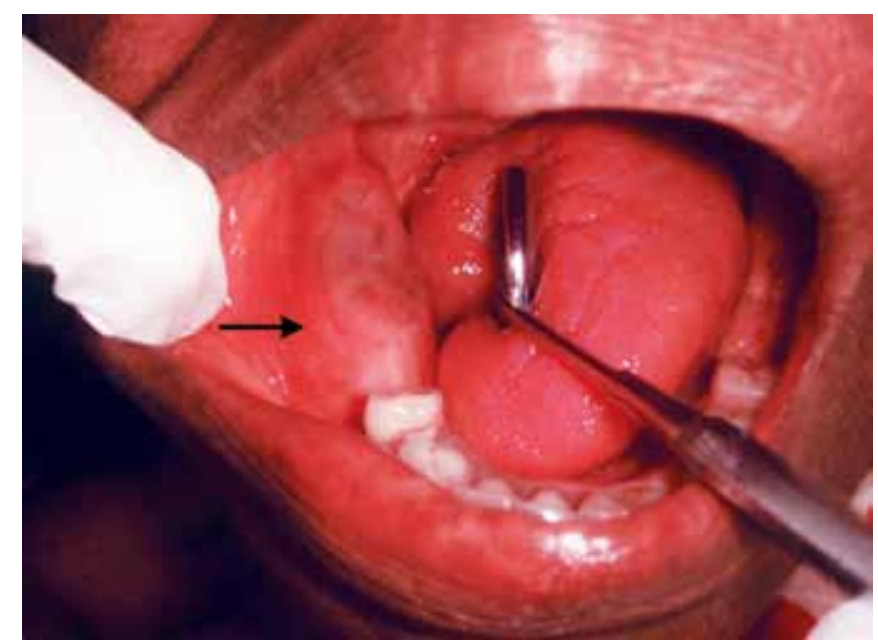

Fig. 1: Intra-oral examination revealing a swelling on the right mandibular residual alveolar ridge extending form the second premolar posterior to the retromolar region

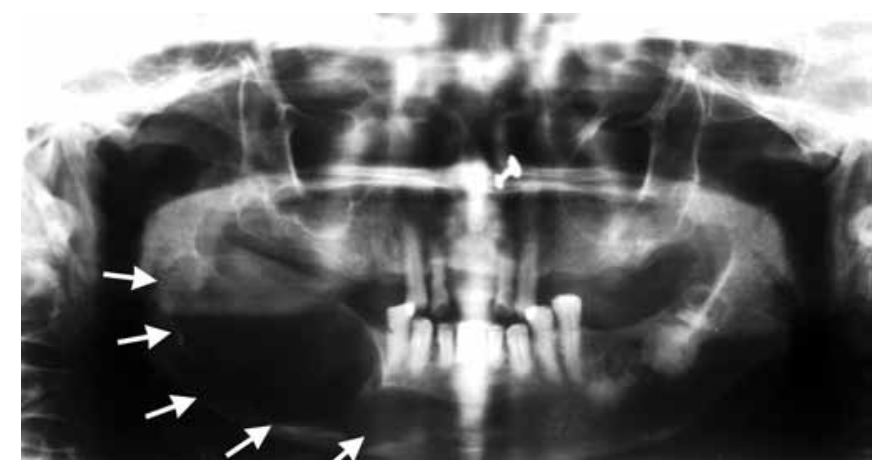

Fig. 2: Panoramic radiograph showing a well defined unilocular radiolucency extending from the right ramus to left canine crossing the midline; Thinning of the lower border of the mandible is also evident

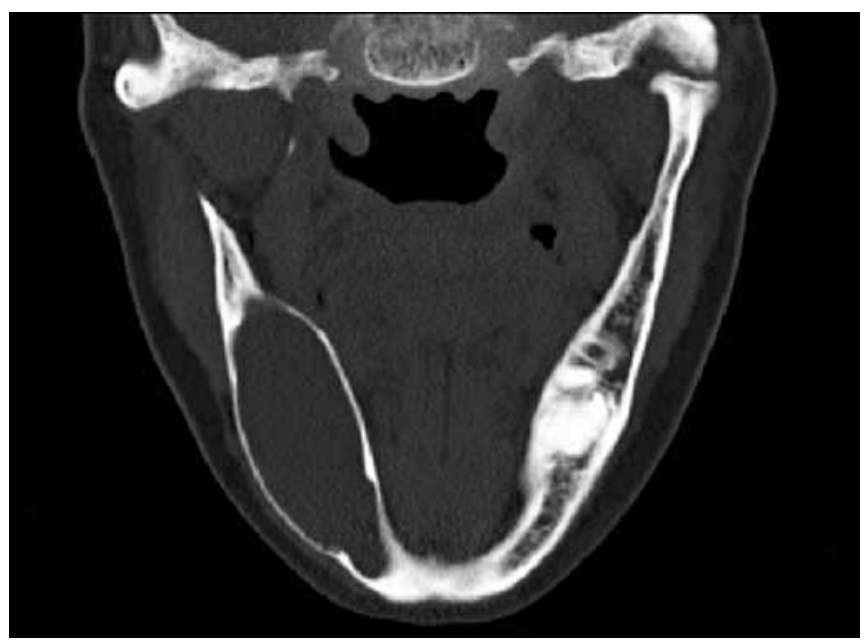

Fig. 3: Plain computerized tomography picture showing a well defined lytic lesion of the mandible 


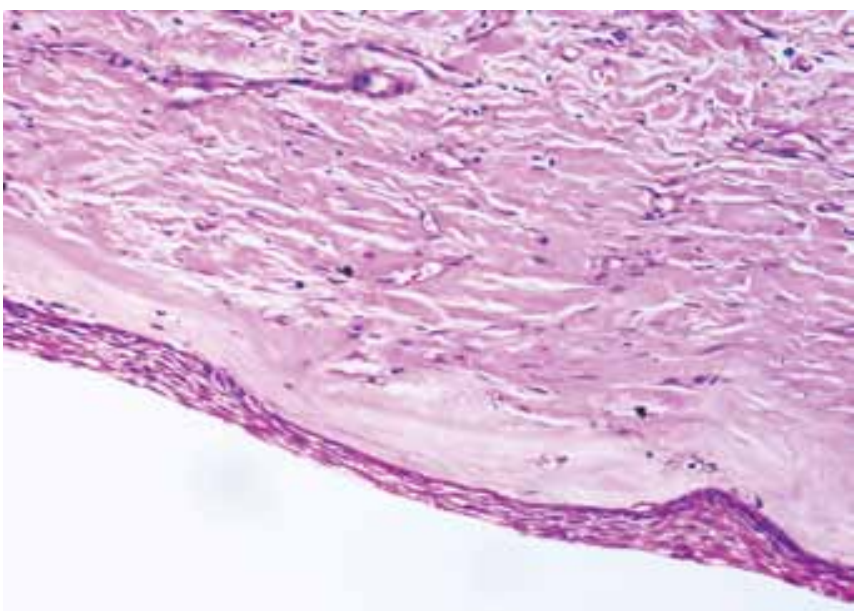

Fig. 4: Photomicrograph showing lining resembling odontogenic epithelium exhibiting stellate reticulum like cells, hyperchromatic basal cells and juxta-epithelial hyalinization ( $\mathrm{H}$ and $\mathrm{E}$ stain at $\times 20$ magnification)

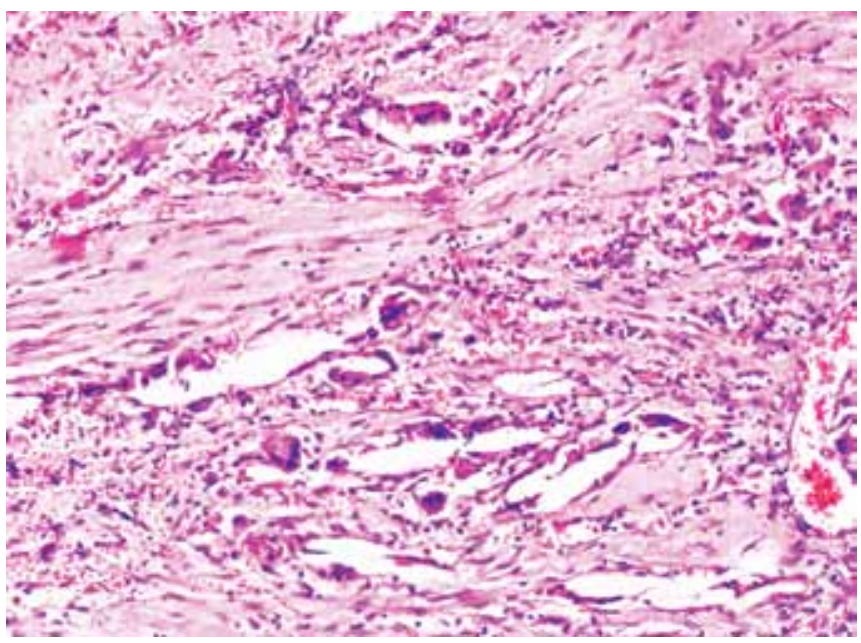

Fig. 5: Photomicrograph showing cholesterol clefts and giant cells ( $\mathrm{H}$ and $\mathrm{E}$ at $\times 20$ magnification)

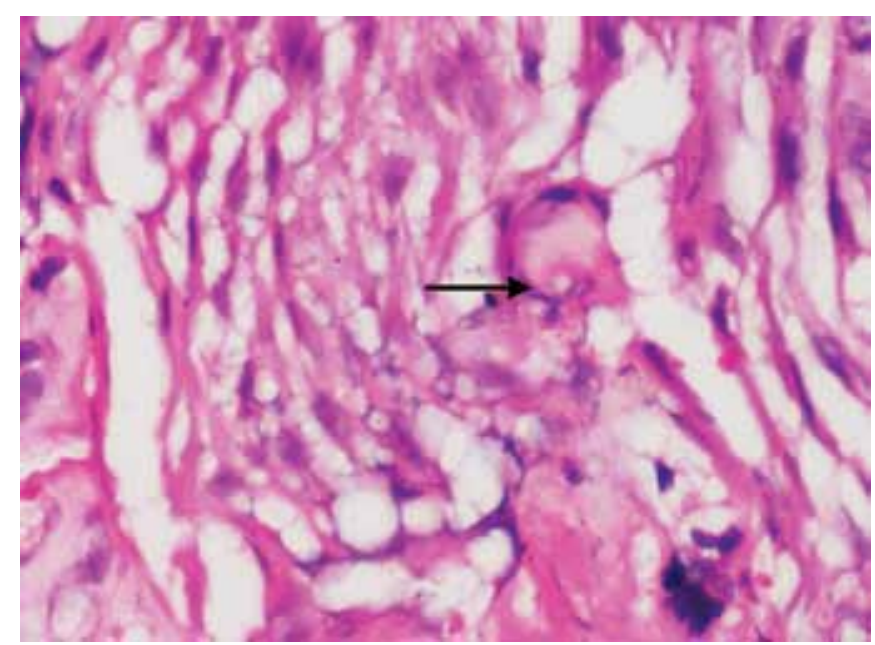

Fig. 6: Photomicrograph showing ghost cells ( $\mathrm{H}$ and $\mathrm{E}$ stain at $\times 10$ magnification)

proliferative activity that lack the Vickers and Gorlin criteria of ameloblast-like cells. Ghost cells may be seen as individual units or in clusters. ${ }^{4,8}$ Herniation of the ghost

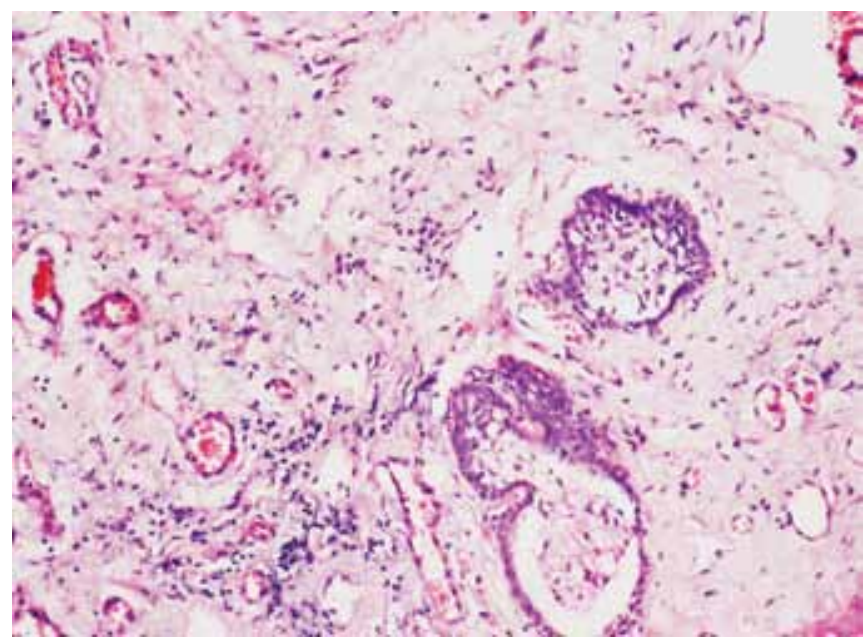

Fig. 7: Photomicrograph showing areas of ameloblastomaotus proliferation ( $\mathrm{H}$ and $\mathrm{E}$ stain at $\times 20$ magnification)

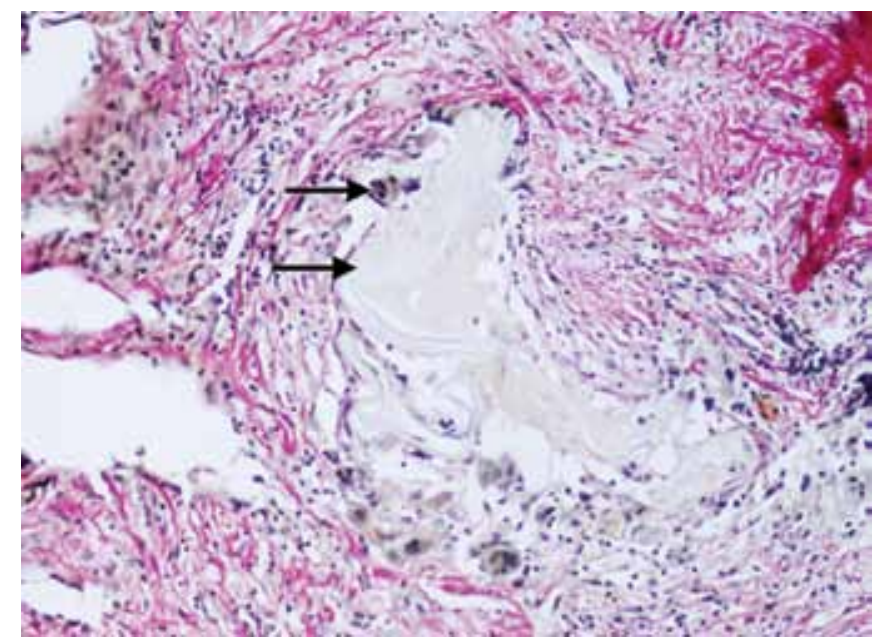

Fig. 8: Photomicrograph of ghost cells in the connective tissue evoking foreign body giant cell reaction (Van Gieson at $\times 20$ magnification)

cells into the connective tissue evokes a foreign body giant cell reaction. Juxta-epithelial dentinoid may be found. In an extensive review of 92 cases of COCs, Hong et $\mathrm{al}^{8}$ reported just two of them as the ameloblastomatous COCs suggesting that the occurrence of ameloblastomatous $\mathrm{COC}$ is uncommon (Table 1).

Interestingly, the presence numerous longitudinal clefts that were densely packed in the connective tissue capsule, inciting a foreign body giant cell reaction resembled a cholesterol granuloma that is normally associated with an inflammatory odontogenic cyst. The occurrence of these cholesterol crystals in the capsular tissue admixed with areas of ghost cells in $\mathrm{COC}$ was unusual.

Theoretically, these clefts are seen after the amassed cholesterol crystals get washed away during tissue processing. The ubiquitous nature of cholesterol and its presence in blood makes plasma the natural resource, ${ }^{9}$ and hemorrhage is considered to be an initiating factor. ${ }^{10}$ 


\begin{tabular}{clllll}
\multicolumn{5}{c}{ Table 1: Reported cases of ameloblastomatous COC since Hong et al's review } \\
\hline SI. No. & Reference & No. of cases & Age in years/sex & Location & Radiographic features \\
\hline 1. & ${\text { Kamboj et } \mathrm{al}^{4}}^{4}$ & 1 & $58 / \mathrm{F}$ & Right posterior mandible & Multilocular radiolucency \\
2. & ${\text { lida et } \mathrm{ll}^{6}}$ & 1 & $17 / \mathrm{M}$ & Right mandibular body & Multilocular radiolucency \\
3. & ${\text { Aithal et } \mathrm{al}^{7}}_{4}$ & 1 & $28 / \mathrm{F}$ & Left posterior mandible & Multilocular radiolucency \\
4. & Our case & 1 & $68 / \mathrm{F}$ & Right posterior mandible & Unilocular radiolucency \\
\hline
\end{tabular}

M: Male; F: Female

The buildup of cholesterol crystals in the cyst wall and the cystic fluid could result from the circulating plasma lipids, disintegrating erythrocytes of stagnant blood vessels within the lesion or fatty degeneration of the connective tissue in a cavity obstructed by inflammation.

Yamazaki et $\mathrm{al}^{11}$ suggested perlecan to be related to the development of cholesterol granulomas. Perlecan is a basement membrane heparan sulfate proteoglycan synthesized by the stromal cells of the granulation tissue and hence widely expressed in it. The deposition of cholesterol crystals in the cyst wall is due to binding of low density lipoprotein (LDL) to its LDL receptor-like domain. Lipid thus accumulated is oxidized in the extracellular space, which is then preferentially taken up by the macrophages. The protein coat is digested and the lipid is released into the extracellular space on apoptosis or necrosis of macrophages. In the absence of the enzyme lecithincholesterol acyltransferase in the cyst fluid, cholesterol is not esterified and crystallizes in the cyst wall (Fig. 9).

The deposited cholesterol crystals act as an irritant and attract macrophages and giant cells. Macrophages convert the hydrophobic cholesterol crystals into a soluble form by incorporating it into a lipoprotein vehicle. However when the crystals are large, they resist internalization by macrophages, which then circumfuse to form multinucleated giant cells. Although they persist for prolonged periods, the phagocytes fail to degrade cholesterol, release inflammatory and bone resorptive mediators which cause further loss of bone and extension of the lesion. ${ }^{12}$

A COC in the setting of a cholesterol granuloma is exceedingly rare. In the present case, the origin of the cholesterol clefts could be related to areas of hemorrhage due to the rupturing of blood vessels perhaps due to repeated fine needle aspiration. The occurrence of hemorrhage in COC has been reported by Martin-Duverneuil et al. ${ }^{13}$ In addition to the foreign body reaction that occurred in response to hemorrhage in the connective tissue wall, the giant cell reaction may also occur secondary to the herniation of ghost cells into the connective tissue as was noted in our case. This feature is clinically significant as the foreign body giant cells may elaborate certain bone resorbing factors and thereby delay the process of bone healing. This was possibly the reason the cyst described here was extensively osteolytic.

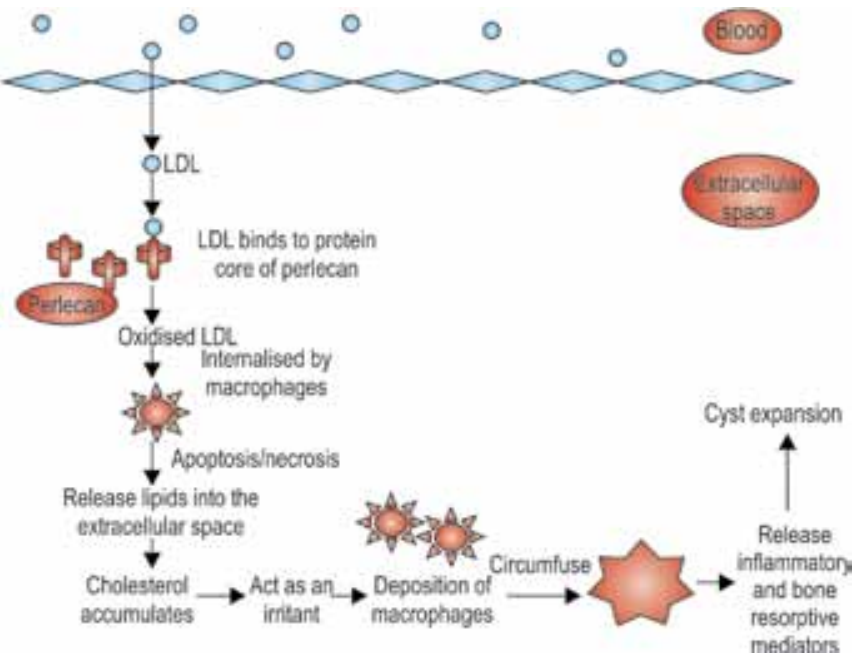

Fig. 9: Schematic representation of cholesterol granuloma formation

\section{CONCLUSION}

Resemblance of the lesion to unicystic ameloblastoma in the incisional biopsy could have lead to an erroneous diagnosis. Identifying the ameloblastomatous variant of $\mathrm{COC}$ and delineating it from unicystic ameloblastoma is essential because of the considerable differences in the treatment. Unicystic ameloblastomas are treated by segmental mandibulectomy due to the greater tendency for recurrence as compared to odontogenic cysts. ${ }^{14}$ Recognition of the true nature of the entity as a calcifying odontogenic cyst obviated the need for hemimandibulectomy. A diagnostician should warrant a high index of suspicion regarding mandibular radiolucencies. The present paper gives an example of the importance of a thorough clinical, radiographic, and histologic examination of all lesions.

\section{REFERENCES}

1. Gorlin RJ, Pindborg JJ, Odont, Clausen FP, Vickers RA. The calcifying odontogenic cyst: a possible analogue of the cutaneous calcifying epithelioma of Malherbe. An analysis of fifteen cases. Oral Surg Oral Med Oral Pathol 1962;15:1235-1243.

2. Tajima Y, Yokose S, Sakamoto E, Yamamoto Y, Utsumi N. Ameloblastoma arising in calcifying odontogenic cyst. Report of a case. Oral Surg Oral Med Oral Pathol 1992;74:776-779.

3. Takeda Y, Suzuki A, Yamamoto H. Histopathologic study of epithelial components in the connective tissue wall of unilocular type of calcifying odontogenic cyst. J Oral Pathol Med 1990;19: 108-113.

4. Kamboj M, Juneja M. Ameloblastomatous Gorlin's cyst. J Oral Sci 2007;49:319-323. 
5. Fregnani ER, Pires FR, Quezada RD, Shih IeM, Vargas PA, de Almeida OP. Calcifying odontogenic cyst: clinicopathological features and immunohistochemical profile of 10 cases. J Oral Pathol Med 2003;32:163-70.

6. Iida S, Ueda T, Aikawa T, Kishino M, Okura M, Kogo M. Ameloblastomatous calcifying odontogenic cyst in the mandible. Dentomaxillofac Radiol 2004;33:409-412.

7. Aithal D, Reddy BS, Mahajan S, Boaz K, Kamboj M. Ameloblastomatous calcifying odontogenic cyst: a rare histologic variant. J Oral Pathol Med 2003;32:376-378.

8. Hong SP, Ellis GL, Hartman KS. Calcifying odontogenic cyst. A review of 92 cases with reevaluation of their nature as cysts or neoplasms, the nature of ghost cells, and subclassification. Oral Surg Oral Med Oral Pathol 1991;72:56-64.

9. Friedmann I, Graham MD. The ultrastructure of cholesterol granuloma of the middle ear: an electron microscope study. The Journal of Laryngology and Otology 1979;93:433-442.

10. Leon ME, Chavez C, Fyfe B, Nagorsky MJ, Garcia FU. Cholesterol granuloma of the maxillary sinus. Arch Pathol Lab Med 2002;126:217-219.

11. Yamazaki M, Cheng J, Hao N, Takagi R, Jimi S, Itabe H, Saku T. Basement membrane-type heparan sulfate proteoglycan (perlecan) and low-density lipoprotein (LDL) are colocalized in granulation tissues: a possible pathogenesis of cholesterol granulomas in jaw cysts. J Oral Pathol Med 2004;33:177-184.

12. Nair PN, Sjögren U, Sundqvist G. Cholesterol crystals as an etiological factor in non-resolving chronic inflammation: an experimental study in guinea pigs. Eur J Oral Sci 1998;106: 644-650.

13. Martin-Duverneuil N, Roisin Hausson M, Behin A, FavreDauvergne E, Chiras J. Combined benign odontogenic tumors: $\mathrm{CT}$ and MR findings and Histomorphologic Evaluation. Am J Neuroradiol 2001;22:867-872.

14. Rosenstein T, Pogrel MA, Smith RA, Regezi JA. Cystic ameloblastoma-behavior and treatment of 21 cases. J Oral Maxillofac Surg 2001;59:1311-1316.

\section{ABOUT THE AUTHORS}

\section{Manikkath Aparna}

Postgraduate Student, Department of Oral and Maxillofacial Pathology Manipal College of Dental Sciences, Manipal, Karnataka, India

\section{Mukund Gupta}

Postgraduate Student, Department of Oral and Maxillofacial Surgery Manipal College of Dental Sciences, Manipal, Karnataka, India

\section{Nanditha Sujir}

Postgraduate Student, Department of Oral Medicine and Radiology Manipal College of Dental Sciences, Manipal, Karnataka, India

\section{Abhay Kamath}

Professor and Head, Department of Oral and Maxillofacial Surgery Manipal College of Dental Sciences, Manipal, Karnataka, India

\section{Monica Solomon}

Professor, Department of Oral and Maxillofacial Pathology, Manipal College of Dental Sciences, Manipal, Karnataka, India

\section{Keerthilatha Pai}

Professor and Head, Department of Oral Medicine and Radiology Manipal College of Dental Sciences, Manipal, Karnataka, India

\section{Raghu Radhakrishnan (Corresponding Author)}

Professor and Head, Department of Oral and Maxillofacial Pathology Manipal College of Dental Sciences, Manipal, Karnataka, India, e-mail: raghu.radhakrishnan@gmail.com 